\title{
Assessment of hemodynamic and vascular parameters in Alzheimer's disease, vascular dementia and mild cognitive abnormalities: a pilot study
}

José Ivany dos Santos'

Chrystian Junior Rodrigues ${ }^{1}$ Juliana Barroso Zogheib' Marcus Vinícius Bolívar Malachias? Bruno Almeida Rezende ${ }^{\mathrm{T}}$

\section{Abstract}

Objectives: this pilot study correlated cardiovascular parameters such as atherosclerosis and arterial stiffness in patients with aged-related dementia and sought to identify hemodynamic differences that can help in differential diagnosis. Method: a longitudinal prospective study was performed of 46 patients aged 60 to 80 years in the city of Belo Horizonte, Minas Gerais, Brazil. The patients were classified into three groups: those with Alzheimer's disease (AD), vascular dementia (VD) or mild cognitive impairment (MCI). The groups were classified by clinical examination and CT or magnetic resonance imaging tests of the encephalon. The arterial stiffness and other hemodynamic parameters of the patients were measured using the Mobil-O-Graph device and carotid artery ultrasound scanning. Data analysis was performed by descriptive statistics, multinomial logistic regression and analysis of variance. Results: 18 patients (39.1\%) had MCI, 18 (39.1\%) AD and $10(21.8 \%)$ VD. Image exams revealed greater obstructive microangiopathy in the AD group than the MCI group $(p<0.05)$, which in turn exhibited greater normality in such tests than the AD group $(p<0.05)$. There were no significant differences among the groups for the hemodynamic variables. The carotid artery ultrasound examinations identified a greater degree of normality in the MCI group than the AD group $(p<0.05)$. Conclusion: the results do not support the idea of using noninvasive hemodynamic evaluation methods as additional exams in the differential diagnosis of these pathologies.
Keywords: Dementia, Vascular. Alzheimer Disease. Pulse Wave Analysis. Vascular Stiffness.
Faculdade de Ciências Médicas de Minas Gerais, Programa de Pós-Graduação em Ciências da Saúde. Belo Horizonte, MG, Brasil.

Research funding: Fundação de Amparo a Pesquisa do Estado de Minas Gerais (Minas Gerais State Research Support Foundation) (FAPEMIG). Bid Invitation II FCMMG-PIBIC/FAPEMIG 2015, development module: scientific initiation grant.

Correspondence

Bruno Almeida Rezende

E-mail: bruno.rezende@cienciasmedicasmg.edu.br 


\section{INTRODUCTION}

The increased risk of cognitive decline that comes with aging constitutes a public health problem due to its strong association with disability and morbidity and mortality. The prevalence of dementia increases with age, affecting about $7 \%$ of individuals aged over 65 years and $30 \%$ of those over $80^{1}$.

The role of the vascular component in cognitive decline has been increasingly investigated. Several studies have shown that individuals with cardiovascular risk factors and vascular disorders have an increased chance of developing cognitive disorders, including not only vascular dementia (VD), but also Alzheimer's disease (AD) ${ }^{2-4}$. In a recent study, cardiovascular risk factors and risk factors for strokes demonstrated a significant predictive value in cognitive decline in 10 years ${ }^{5}$.

VD and AD are two main types of irreversible dementias and represent respectively $60 \%$ and $20 \%$ of all conditions. Dementias are also represented, to a lesser extent, by Parkinson's disease, frontotemporal dementia and Lewy body dementia. When the clinical manifestations include characteristics of AD and $\mathrm{VD}$, it is known as mixed dementia ${ }^{6,7}$.

Literature on the subject reveals that the etiopathogenesis of dementias is defined by multiple factors involving genetic and metabolic causes and the aging of the brain itself. Some studies have shown that vascular disease worsens with advancing age and that there may be a relationship between vascular pathologies and increased risk of denentias $^{2,4}$. Vascular disorders in AD and altered blood flow in the brain suggest that dementia may be a vascular disorder with neurodegenerative consequences ${ }^{8}$.

Better knowledge about the vascular alterations present in individuals with AD and VD can help to provide earlier diagnosis and change the perspectives of cognitive decline.
We therefore sought to establish a relationship between the results of central nervous system images, ultrasound examinations of the carotid arteries and measurement of pulse wave velocities in the peripheral arteries in individuals with dementia related to age and to verify if the same can be used in the differential diagnosis of AD and VD or mild cognitive impairment (MCI), in the city of Belo Horizonte, in the state of Minas Gerais, Brazil.

\section{METHODS}

A prospective and longitudinal pilot study was performed of elderly people of both genders, aged 60 to 80 years, with complaints of cognitive decline, who received care from a private practice in the city of Belo Horizonte, Minas Gerais, Brazil, between April 2015 and May 2016. The sample consisted of 46 individuals and was based on convenience by recruiting patients who sought the clinic with complaints of cognitive decline and who met the inclusion criteria during the study period.

The patients were classified into three groups based on clinical tests and images used routinely in the diagnosis of age related dementia (AD, VD and $\mathrm{MCI})$. Once the groups were classified, we performed noninvasive assessments of the vascular condition of these patients and searched for differences between these parameters in the different groups to verify if these parameters could serve as a diagnostic tool to help identify the different dementias related to age. The subjects admitted to the study underwent clinical evaluation and neuroimaging laboratory tests such as computed tomography (CT) or magnetic resonance imaging (MRI) of the brain and the application of biochemical tests (Chart 1), with the objective of detecting disorders associated with the subject of the study and to exclude conditions or diseases related to profiles that may be characterized as non-MCI, VD or AD cognitive disorders, such as depressive disorders, neurological diseases, dementias related to Parkinson's disease, Lewy bodies, frontal lobe, mixed, metabolic or infectious causes. 
Chart 1. Biochemical tests and imaging exams used in the clinical evaluation of patients. Belo Horizonte, 2016.

\begin{tabular}{|l|l|}
\hline Biochemical Tests & $\begin{array}{l}\text { Hemoglobin, glucose, total cholesterol and fractions, triglycerides, thyroid stimulating } \\
\text { hormone, sodium, potassium, urea, creatinine, ionic calcium, transaminases, vitamin B12, } \\
\text { folic acid and VDRL }\end{array}$ \\
\hline Imaging Exams & Nuclear magnetic resonance of the encephalon or computed tomography of the encephalon. \\
\hline $\begin{array}{l}\text { Ultrasound examination } \\
\text { of the carotid arteries }\end{array}$ & Duplex scan of the carotid arteries \\
\hline
\end{tabular}

VDRL: Venereal Disease Research Laboratory (test for diagnosis of syphilis).

The subjects selected for the survey underwent the following clinical tests for classification purposes: Geriatric Depression Scale (GDS-15)'; Mini Mental State Exam ${ }^{10}$; Clock Drawing Test ${ }^{11}$; Image recognition test ${ }^{12}$; Language test (animals and fruit $)^{13}$; Clinical Dementia Rating $(\mathrm{CDR})^{14}$; Evaluation of Activities of Daily Living and Instrumental Activities of Daily Living.

The examinations and tests used to classify the patients into the different groups are part of the overall geriatric assessment of people who present memory disorders or other cognitive alterations and therefore did not entail additional costs for the participants. The patients fasted for 10 to 12 hours prior to the biochemical exams and no previous preparation was necessary for the clinical imaging and evaluation exams by cognitive tests.

Elderly patients with cognitive disorders without impairment of activities of daily living (ADLs) and instrumental activities of daily living (IADLs) and who had scores within normal values adjusted for level of schooling according to the methodology proposed by Pfeffer ${ }^{15}$ were defined as having MCI. Mild to moderate dementia was defined when the tests showed disorders in the cognitive tests and impairment for ADLs and IADLs. Mild dementia was when there was impairment of an ADL or IADL and moderate impairment of more than one ADL or IADL ${ }^{15}$.

After screening, study participants were organized into three groups. The description of each study group is given in Chart 2.

All patients underwent brain imaging (CT or MRI) with the purpose of evidencing cortex or vascular lesions that could aid in the diagnosis and classification of the groups. If the imaging tests indicated an uncertain classification the subject was excluded from the study. It should be emphasized that both CT and MRI scans can be used as a tool to diagnose different types of dementia related to age ${ }^{7}$. Some patients involved in the study had been referred by other physicians or had the results of a previous MRI or CT exam with them. In such cases the existing examinations were used so the patients did not have to undergo the exam again. If the patient had not undergone an imaging test a CT was requested.

Chart 2. Description of three groups of patients. Belo Horizonte, MG, 2016.

\begin{tabular}{|l|l|l|}
\hline $\begin{array}{l}\text { Control Group } \\
\text { Mild cognitive impairment }\end{array}$ & $\begin{array}{l}\text { AD Group } \\
\text { Alzheimer's Disease }\end{array}$ & $\begin{array}{l}\text { VD Group } \\
\text { Vascular Dementia }\end{array}$ \\
\hline $\begin{array}{l}\text { Individuals aged between } 60 \text { and } 80 . \\
\text { Mild cognitive impairment with no } \\
\text { evidence of dementias. }\end{array}$ & $\begin{array}{l}\text { Individuals aged between } 60 \text { and } 80 . \\
\text { Alzheimer's Disease, with mild to } \\
\text { moderate cognitive impairment, } \\
\text { and no neurological impairment } \\
\text { that prevented the individual from } \\
\text { undergoing cognitive tests and } \\
\text { laboratory evaluations. }\end{array}$ & $\begin{array}{l}\text { Individuals aged between } 60 \text { and } 80 . \\
\text { Vascular Dementia, with mild to } \\
\text { moderate cognitive deficits, and } \\
\text { prevented the individual from } \\
\text { undergoing cognitive tests and } \\
\text { laboratory evaluations. }\end{array}$ \\
\hline
\end{tabular}


After being classified in one of the three groups all the patients were submitted to an ultrasound scan by carotid artery duplex scan to assess the degree of impairment of these vessels. Duplex Scan or vascular ultrasound consists of the use of a multi-frequential linear transducer placed in the territory of the vessel to be studied (carotid and vertebral arteries), in the anterolateral region of the neck. A gel is applied to the base of the device that forms a column that facilitates the propagation of the ultrasound for the study of the vessels. The examination provides information on the anatomical-functional nature of the arteries, which allows the evaluation of intimamedia thickness, atherosclerotic impairment, and the presence of plaques and obstructive processes that may compromise blood flow. No preparation is required for the exam. The inherent risks of the procedure are minimal, and are associated with the amount of time the patient spends in the decubitus position, which may result in dizziness when rising. This passes after a few minutes in the supine position, however.

Measurement of arterial stiffness in the brachial artery was performed automatically using the Mobil-O-Graph noninvasive equipment, by means of oscillometric measurements in the upper limb. This equipment uses a classic MAPA device for measuring long-term blood pressure and offers the option of calculating arterial stiffness through Pulse Wave Analysis (PWA). The device involves placing a sensor-coupled cuff on the right upper limb of the patient, after measurement of the perimeter of the limb and choice of the appropriate cuff. No previous patient preparation is necessary and the examination takes about eight minutes.

The Mobil-O-Graph device used to obtain the hemodynamic data can provide a series of useful results in the evaluation of the vascular condition of patients ${ }^{17}$. Using a specific software program (HMS Client-Server data management software) the equipment correlates the measurements of $\mathrm{BP}$ and PWA with data provided, such as weight, height, age, and performs several mathematical calculations involving algorithms that provide indicators of the vascular condition of the individual. The present study mainly used the PWA results, which has been recommended as an indicator of arterial stiffness in several studies, and has been used as an auxiliary tool to diagnose conditions related to vascular pathologies ${ }^{17,18}$. In addition to the hemodynamic indicators, the software coupled to the device also provides body mass index (BMI) and body surface area data, which were also used in this study. All the data presented in Table 3 were obtained from the report prepared for each patient issued by the HMS Client-Server data management software.

The Mobil-O-Graph measurements are rated by the instrument into signal strength levels ranging from 1 (best signal level) to 5 (worst signal level). For each patient, three measures were considered, all which had level 1, 2 or 3 signal strength levels. The level 4 and 5 measurements were discarded as recommended by the validation study ${ }^{17}$.

The results of all the variables determined by the Mobil-O-Graph were organized and the three groups of individuals were compared.

All the examiners in the present study underwent training to calibrate the results. The clinical evaluation of the patients was carried out by a geriatrician, the measurements of the hemodynamic parameters were taken by two students of the medicine course accompanied by a cardiologist, and the imaging examinations were performed by a specialist in this area.

The inclusion criteria of the study were patients aged 60 to 80 years diagnosed as having AD or VD or MCI according to the clinical and imaging tests cited throughout the methodology of this study. The exclusion criteria included patients who did not undergo all the clinical or imaging or biochemical examinations essential for group classification studied, those aged over 70 without a companion, and patients with uncertain classifications or mixed dementias.

The qualitative variables were presented as absolute and relative frequencies and the quantitative data as mean $\pm S D$. The quantitative variables were submitted to the Shapiro-Wilk normality test. The association between categorical variables was assessed through multinomial logistic regression. Single factor variance was used for the comparison of the means of the three groups. The analyzes were developed in software $\mathrm{R}$ version 3.2.2 and a level of significance of $5 \%$ was applied. 
The elderly with mild cognitive impairment and those under the age of 70 signed a Free and Informed Consent Form (FICF) after clarification of any questions about the study. Patients with moderate dementia or aged over 70 , regardless of the degree of cognitive impairment, had the FICF signed by their accompanying legal guardian.

The present study was submitted to the Minas Gerais Medical Science Research Ethics Committee (CAAE: 36417014.4.0000.5134) and approved (approval number: 875.058).

\section{RESULTS}

The sample of the present study consisted of 46 individuals of whom 25 were women and 21 were men. Of the subjects participating in the study, 18 (39.1\%) belonged to the MCI group, 18 (39.1\%) to the AD group and $10(21.8 \%)$ to the VD group. The mean age, BMI and body surface area of the participants were $74.07 \pm 5.03$ years, $26.06 \pm 4.46 \mathrm{~kg} /$ $\mathrm{m}^{2}$ and $1.73 \pm 0.19 \mathrm{~m}^{2}$, respectively.
There was a higher proportion of individuals with normal echographic findings in the MCI group $(44 \%)$ than in the AD group (6\%, $p$-value 0.025$)$. We did not find a direct association between large lesions of the carotid arteries and dementia. There was a greater predominance of atheromatosis in the carotid artery in $\mathrm{AD}(72 \%)$ and $\mathrm{VD}(80 \%)$ patients than in individuals with MCI (38\%). These data were not statistically significant for the sample of the present study, however. (Table 1).

A higher proportion of individuals with normal brain imaging findings was found in the MCI group $(44 \%)$ than in the $\mathrm{AD}$ group $(0 \%, p$-value 0.020$)$. Obstructive microangiopathy was more prevalent in the $\mathrm{AD}$ group $(72 \%)$ than the MCI group $(17 \%$, $p$-value 0.008) (Table 2).

No significant differences were found in the cardiovascular indicators of arterial stiffness measured in the brachial artery by the indirect PWA method for any of the variables studied, as can be seen in Table 3.

Table 1. Ultrasound findings assessed by duplex carotid artery scan with numerical and percentage representation for each group. Belo Horizonte, Minas Gerais, 2016.

\begin{tabular}{lllll}
\hline Ultrasound findings & \multicolumn{2}{c}{ Groups } & Total \\
& $\begin{array}{l}\text { MCI } \\
\mathrm{n}(\%)\end{array}$ & $\begin{array}{l}\text { AD } \\
\mathrm{n}(\%)\end{array}$ & $\mathrm{nD}(\%)$ & $\mathrm{n}(\%)$ \\
\hline Normal & $8(44)^{*}$ & $1(06)^{*}$ & $0(00)$ & $9(19)$ \\
\hline Stenosis lower than $60 \%$ & $1(06)$ & $1(06)$ & $2(20)$ & $4(09)$ \\
\hline Atheromatosis & $7(38)$ & $13(72)$ & $8(80)$ & $28(61)$ \\
\hline Increase in intima-media thickness & $2(12)$ & $3(16)$ & $0(00)$ & $5(11)$ \\
\hline Total & $18(100)$ & $18(100)$ & $10(100)$ & $46(100)$ \\
\hline
\end{tabular}

MCI: mild cognitive impairment; AD: Alzheimer's disease; VD: vascular dementia; *Significant differences between pairs $(p<0.05)$ evaluated through multinomial logistic regression. 
Table 2. Imaging findings from computed tomography of the encephalon or magnetic resonance of the encephalon. Belo Horizonte, Minas Gerais, 2016.

\begin{tabular}{lllll}
\hline Encephalon image finding & MCI & AD & Groups & Total \\
& $\mathrm{n}(\%)$ & $\mathrm{n}(\%)$ & $\mathrm{n}(\%)$ & $\mathrm{n}(\%)$ \\
\hline Normal & $8(44)^{*}$ & $0(00)^{*}$ & $0(00)$ & $8(17)$ \\
\hline Age-compatible atrophy & $7(39)$ & $2(11)$ & $0(00)$ & $9(20)$ \\
\hline Obstructive microangiopathy & $3(17)^{*}$ & $13(72)^{*}$ & $0(00)$ & $16(35)$ \\
\hline Atrophy in the hippocampus & $0(00)$ & $2(11)$ & $0(00)$ & $2(04)$ \\
\hline Lacunar infarcts & $0(00)$ & $0(00)$ & $7(70)$ & $7(15)$ \\
\hline Ischemic injuries & $0(00)$ & $1(06)$ & $3(30)$ & $4(09)$ \\
\hline Total & $18(100)$ & $18(100)$ & $10(100)$ & $46(100)$ \\
\hline
\end{tabular}

MCI: mild cognitive impairment; AD: Alzheimer's disease; VD: vascular dementia; *Significant differences between pairs $(\mathrm{p}<0.05)$ evaluated through multinomial logistic regression.

Table 3. Comparison of data obtained for groups studied from Software HMS Client-Server data management reports. Belo Horizonte, MG, 2016.

\begin{tabular}{|c|c|c|c|c|}
\hline Variables & $\begin{array}{l}\text { MCI } \\
\text { Mean } \pm \text { sd }\end{array}$ & $\begin{array}{l}\text { AD } \\
\text { Mean } \pm \text { sd }\end{array}$ & $\begin{array}{l}\text { VD } \\
\text { Mean } \pm \text { sd }\end{array}$ & $p$-valor \\
\hline Age (years) & $72.89 \pm 4.57$ & $75.83 \pm 4.45$ & $72.89 \pm 6.39$ & 0.158 \\
\hline $\mathrm{BMI}\left(\mathrm{kg} / \mathrm{m}^{2}\right)$ & $26.17 \pm 3.61$ & $26.46 \pm 5.44$ & $25.12 \pm 4.19$ & 0.749 \\
\hline Body surface $\left(\mathrm{m}^{2}\right)$ & $1.76 \pm 0.21$ & $1.71 \pm 0.18$ & $1.72 \pm 0.13$ & 0.708 \\
\hline Peripheral systole $(\mathrm{mmHg})$ & $125.84 \pm 18.31$ & $127.74 \pm 20.99$ & $132.84 \pm 16.69$ & 0.649 \\
\hline Peripheral diastole (mmHg) & $77.19 \pm 10.05$ & $74.10 \pm 14.25$ & $79.66 \pm 15.33$ & 0.540 \\
\hline Mean blood pressure $(\mathrm{mmHg})$ & $99.49 \pm 13.21$ & $98.67 \pm 16.44$ & $103.96 \pm 14.75$ & 0.650 \\
\hline Pulse pressure (mmHg) & $48.71 \pm 11.88$ & $53.64 \pm 12.75$ & $53.17 \pm 12.44$ & 0.446 \\
\hline Heart rate (bps) & $76.48 \pm 12.11$ & $71.38 \pm 10.21$ & $67.57 \pm 9.91$ & 0.112 \\
\hline Central systole $(\mathrm{mmHg})$ & $114.82 \pm 16.90$ & $115.71 \pm 18.91$ & $118.67 \pm 16.43$ & 0.855 \\
\hline Central diastole $(\mathrm{mmHg})$ & $78.06 \pm 10.91$ & $75.4 \pm 14.38$ & $82.09 \pm 15.28$ & 0.451 \\
\hline Central pulse pressure $(\mathrm{mmHg})$ & $36.39 \pm 9.90$ & $40.13 \pm 9.62$ & $36.58 \pm 5.76$ & 0.414 \\
\hline Pulse Width Amplification & $1.38 \pm 0.17$ & $1.34 \pm 0.09$ & $1.46 \pm 0.24$ & 0.180 \\
\hline Systolic volume (ml) & $71.32 \pm 14.24$ & $67.91 \pm 11.09$ & $74.29 \pm 11.01$ & 0.416 \\
\hline Cardiac output (l/min) & $5.29 \pm 0.73$ & $4.76 \pm 0.60$ & $5.23 \pm 0.79$ & 0.065 \\
\hline Total vascular resistance $(\mathrm{mmHg} / \mathrm{ml})$ & $1.14 \pm 0.12$ & $1.26 \pm 0.27$ & $1.24 \pm 0.29$ & 0.262 \\
\hline Cardiac output & $3.03 \pm 0.43$ & $2.86 \pm 0.58$ & $3.07 \pm 0.51$ & 0.485 \\
\hline Pressure augmentation $(\mathrm{mmHg})$ & $7.44 \pm 3.06$ & $12.30 \pm 8.10$ & $9.33 \pm 5.47$ & 0.061 \\
\hline Reflection coefficient $(\%)$ & $68.64 \pm 9.81$ & $68.29 \pm 9.01$ & $61.68 \pm 9.47$ & 0.143 \\
\hline Augmentation index $\left(\mathrm{L} / \mathrm{min} / \mathrm{m}^{2}\right)$ & $19.99 \pm 9.59$ & $25.09 \pm 9.82$ & $20.57 \pm 9.28$ & 0.251 \\
\hline Pulse wave velocity $(\mathrm{m} / \mathrm{s})$ & $10.48 \pm 1.13$ & $11.14 \pm 1.18$ & $10.83 \pm 1.34$ & 0.258 \\
\hline
\end{tabular}

MCI: mild cognitive impairment; AD: Alzheimer's disease; VD: vascular dementia; BMI: body mass index; Comparison between groups in relation to the measurements (mean $\pm \mathrm{sd}$ ). $P$-values refer to single-factor analysis of variance. 


\section{DISCUSSION}

Since 1955, dementias related to aging have been classified into two types: VD, caused by focal atrophic ischemic lesions, and $\mathrm{AD}$, caused by cortical neurodegenerative process ${ }^{19}$. Differentiation between the two types of dementias is often difficult and involves a number of clinical tests and imaging exams. Identifying the type of dementia is extremely important as treatment depends on the correct diagnosis ${ }^{7,19}$.

Based on imaging and cognitive tests, the 46 patients evaluated in this study were classified into three groups (AD, VD and MCI). As recorded in Table 3, the sample was largely homogeneous and there was no statistical difference in the BMI, ages or body surface areas of the three groups evaluated.

In the present study, ultrasonographic findings assessed by carotid artery duplex scanning (Table 1) were not directly associated with large lesions of the carotid arteries and dementia. Some works in literature have stated that stenosis of the large cranial vessels and atherosclerosis are risk factors for the development of dementia ${ }^{20,21}$. The BarcelonaAsia study (2013) involving 714 Caucasian subjects failed to find an independent association between stenosis of the large intracranial vessels and a decline in cognitive performance ${ }^{22}$, which corroborates the findings of the present study and also the results obtained by Suemoto et al. ${ }^{20}$ which failed to correlate an increase in intima-media thickness with a higher prevalence of cognitive decline. However, some studies still suggest that such damage may be an indicator of the evolution of these profiles to cognitive decline ${ }^{23,24}$.

The neuroimaging examinations (Table 2) were used to exclude expansive lesions such as subdural hematomas, hydrocephalus, tumors, granulomas or other images that might be associated with non-dementia profiles. DA. Wiederkehr et al. ${ }^{25}$ demonstrated that no neuropathological marker exists that can be widely used for the diagnosis of VD. In this study, the findings of lacunar infarcts and well-defined ischemic lesions, when combined with clinical evaluation, cognitive decline and Hakinski scale scores greater than 4 , were classified as $\mathrm{VD}^{25,26}$.
It was noted that there was a predominance of obstructive microangiopathy in the AD group (Table 2). This finding reinforces the theory that vascular pathogenesis is more present in the small vessels in neurodegenerative disorders associated with cognitive deficits classified as $\mathrm{AD}^{27,28}$.

The sample of the present study was similar to that of other works in literature that evaluated similar parameters in the same population ${ }^{29}$. However, the present study was not able to identify any significant differences in the hemodynamic parameters between the different groups evaluated, unlike the study by Dhoat et al. ${ }^{29}$, which showed, for example, a much higher pulse pressure and augmentation rate among patients with VD than in individuals with $\mathrm{AD}$ and controls. However, as observed in the present study, Dhoat et al. ${ }^{29}$ did not find differences in PWA among the different groups. Three similar studies found higher PWA values in VD patients than in AD groups ${ }^{18,30,31}$. Scuteri et al., meanwhile, using a larger sample (41 patients with VD, 24 with AD and 19 controls) found a small difference in PWA between the VD and AD groups, with the PWA value higher among patients with VD. This differs to the findings of other studies, which identified higher PWA values for patients with $\mathrm{AD}$ than those with $\mathrm{VD}^{18,30,31}$.

Studies that have found an increase in PWA among VD patients in comparison to AD patients mostly propose the use of this parameter as a diagnostic aid for the differentiation between the two types of dementia ${ }^{18,30,31}$. PWA measurement can now be easily obtained using simple equipment in a noninvasive manner and at a relatively low cost. These new devices allow the correlation of PWA with other parameters such as BP and heart rate, making it possible to calculate other variables that may be useful in the prediction of cardiovascular comorbidities ${ }^{17,32}$. Some studies have shown that both VD and AD are strongly associated with cardiovascular risk factors such as hypertension, diabetes and dyslipidemia ${ }^{3,4,33}$. Parameters such as PWA may also be highly influenced by miscellaneous medicinal products such as the antihypertensive vasodilator agents frequently used by elderly people with cognitive impairment ${ }^{34,35}$. Thus, the use of parameters such as PWA in the differential diagnosis of $\mathrm{AD}$ and VD still requires further evaluation. The present study further strengthens 
this idea, as significant differences in noninvasive hemodynamic parameters were not found among patients with VD and AD.

The present study is considered a pilot study and has limitations such as the relatively small number of elderly participants. These parameters can be further studied, in works with larger samples and involving several health services.

\section{CONCLUSION}

The hemodynamic parameters evaluated in this work by noninvasive methods such as pulse wave velocity, central pulse pressure, mean arterial pressure

\section{REFERENCES}

1. Instituto Brasileiro de Geografia e Estatística. Censo Demografico. Brasil. Rio de Janeiro: IBGE; 2010.

2. Gardener H, Caunca MR, Dong C, Cheung YK, Elkind MSV, Sacco RL, et al. Ultrasound markers of carotid atherosclerosis and cognition: the Northern Manhattan Study. Stroke. 2017;48(7):1855-61.

3. Arvanitakis Z, Capuano AW, Leurgans SE, Bennett DA, Schneider JA. Relation of cerebral vessel disease to Alzheimer's disease dementia and cognitive function in elderly people: a cross-sectional study. Lancet Neurol. 2016;15(9):934-43.

4. Wolters FJ, Zonneveld HI, Hofman A, Van der Lugt A, Koudstaal PJ, Vernooij MW, et al. Cerebral perfusion and the risk of Dementia: a PopulationBased Study. Circulation. 2017;136(12):717-28.

5. Watfa G, Benetos A, Kearney-Schwartz A, Labat C, Gautier S, Hanon O, et al. Do Arterial hemodynamic parameters predict cognitive decline over a period of 2 years in individuals older than 80 years living in nursing homes? The PARTAGE Study. J Am Med Dir Assoc. 2015;16(7):598-602.

6. Scuteri A, Brancati AM, Gianni W, Assisi A, Volpe M. Arterial stiffness is an independent risk factor for cognitive impairment in the elderly: a pilot study. J Hypertens. 2005;23(6):1211-6.

7. Tong T, Ledig C, Guerrero R, Schuh A, Koikkalainen $\mathrm{J}$, Tolonen A, et al. Five-class differential diagnostics of neurodegenerative diseases using random undersampling boosting. Neuroimage Clin. 2017;15:613-24. and other measurements related to arterial stiffness did not differ among individuals with vascular dementia, Alzheimer's dementia or mild cognitive impairment. The results obtained do not support the possibility that these methods can be used in the differential diagnosis of the two pathologies. Studies involving a greater number of research subjects and the involvement of several health services are necessary to confirm these observations.

\section{ACKNOWLEDGEMENTS}

We would like to thank Dr. Isabel Cristina Gomes for her help with the statistical analysis of the present study.

8. Tolppanen AM, Solomon A, Soininen H, Kivipelto M. Midlife vascular risk factors and Alzheimer's disease: evidence from epidemiological studies. J Alzheimers Dis. 2012;32(3):531-40.

9. Almeida OP, Almeida SA. Short versions of the geriatric depression scale: a study of their validity for the diagnosis of a major depressive episode according to ICD-10 and DSM-IV. Int J Geriatr Psychiatry. 1999;14(10):858-65.

10. Folstein MF, Folstein SE, McHugh PR. "Mini-mental state". A practical method for grading the cognitive state of patients for the clinician. J Psychiatr Res. 1975;12(3):189-98.

11. Atalaia-Silva KC, Lourenço RA. Tradução, adaptação e validação de construto do Teste do Relógio aplicado entre idosos no Brasil. Rev Saúde Pública. 2008;42(5):930-7.

12. Nitrini R, Lefèvre BH, Mathias SC, Caramelli P, Carrilho PEM, Sauaia N, et al. Testes neuropsicológicos de aplicação simples para o diagnóstico de demência. Arquivos de NeuroPsiquiatria. 1994;52(4):457-65.

13. Rodrigues AB, Yamashita ET, Chiappetta ALML. Teste de fluência verbal no adulto e no idoso: verificação da aprendizagem verbal. Rev CEFAC. 2008;10(4):443-51.

14. De Moraes FM, Bertolucci PHF. Clinical variables related to the diagnostic stability of demential syndromes. Int Psychogeriatr. 2017;29(10):1735-41. 
15. Pfeffer RI, Kurosaki TT, Harrah CH, Chance JM, Filos S. Measurement of functional activities in older adults in the community. J Gerontol. 1982;37(3):323-9.

16. Nagarkar A, Kashikar Y. Predictors of functional disability with focus on activities of daily living: A community based follow-up study in older adults in India. Arch Gerontol Geriatr. 2017;69:151-5.

17. Franssen PM, Imholz BP. Evaluation of the Mobil-OGraph new generation ABPM device using the ESH criteria. Blood Press Monit. 2010;15(4):229-3

18. Mizushima Y, Oobasawa H, Yoshida S, Irie H, Urata T, Shimoda H. Pulse wave velocity in persons with vascular dementia. J Am Geriatr Soc. 2003;51(9):1329-30.

19. Elahi FM, Miller BL. A clinicopathological approach to the diagnosis of dementia. Nat Rev Neurol. 2017;13(8):457-76.

20. Suemoto CK, Nitrini R, Grinberg LT, Ferretti RE, Farfel JM, Leite RE, et al. Atherosclerosis and dementia: a cross-sectional study with pathological analysis of the carotid arteries. Stroke. 2011;42(12):3614-5.

21. Bos D, Vernooij MW, De Bruijn RF, Koudstaal PJ, Hofman A, Franco OH, et al. Atherosclerotic calcification is related to a higher risk of dementia and cognitive decline. Alzheimers Dement. 2015;11(6):639-47.

22. Reis JP, Launer LJ, Terry JG, Loria CM, Zeki Al Hazzouri A, Sidney S, et al. Subclinical atherosclerotic calcification and cognitive functioning in middleaged adults: the CARDIA study. Atherosclerosis. 2013;231(1):72-7.

23. Buratti L, Balestrini S, Altamura C, Viticchi G, Falsetti L, Luzzi S, et al. Markers for the risk of progression from mild cognitive impairment to Alzheimer's disease. J Alzheimers Dis. 2015;45(3):883-90.

24. Viticchi G, Falsetti L, Vernieri F, Altamura C, Bartolini M, Luzzi S, et al. Vascular predictors of cognitive decline in patients with mild cognitive impairment. Neurobiol Aging. 2012;33(6):1-9.

25. Wiederkehr S, Simard M, Fortin C, Van Reekum R. Comparability of the clinical diagnostic criteria for vascular dementia: a critical review. Part I. J Neuropsychiatry Clin Neurosci. 2008;20(2):150-61.
26. Bowler JV. Vascular cognitive impairment. J Neurol Neurosurg Psychiatry. 2005;76(Suppl 5):35-44.

27. Chui HC. Subcortical ischemic vascular dementia. Neurol Clin. 2007;25(3):717-40.

28. Cai Z, Wang C, He W, Tu H, Tang Z, Xiao M, et al. Cerebral small vessel disease and Alzheimer's disease. Clin Interv Aging. 2015;10:1695-704.

29. Dhoat S, Ali K, Bulpitt CJ, Rajkumar C. Vascular compliance is reduced in vascular dementia and not in Alzheimer's disease. Age Ageing. 2008;37(6):653-9.

30. Hanon O, Haulon S, Lenoir H, Seux ML, Rigaud AS, Safar M, et al. Relationship between arterial stiffness and cognitive function in elderly subjects with complaints of memory loss. Stroke. 2005;36(10):2193-7.

31. Ohmine T, Miwa Y, Yao H, Yuzuriha T, Takashima $\mathrm{Y}$, Uchino A, et al. Association between arterial stiffness and cerebral white matter lesions in community-dwelling elderly subjects. Hypertens Res. 2008;31(1):75-81.

32. Feistritzer HJ, Klug G, Reinstadler SJ, Reindl M, Mayr A, Schocke M, et al. Oscillometric analysis compared with cardiac magnetic resonance for the assessment of aortic pulse wave velocity in patients with myocardial infarction. J Hypertens. 2016;34(9):1746-51.

33. Reed BR, Mungas DM, Kramer JH, Ellis W, Vinters $\mathrm{HV}$, Zarow C, et al. Profiles of neuropsychological impairment in autopsy-defined Alzheimer's disease and cerebrovascular disease. Brain. 2007;130(Pt 3):731-9.

34. Hayoz D, Zappe DH, Meyer MA, Baek I, Kandra A, Joly MP, et al. Changes in aortic pulse wave velocity in hypertensive postmenopausal women: comparison between a calcium channel blocker vs angiotensin receptor blocker regimen. J Clin Hypertens. 2012;14(11):773-8.

35. Raff U, Walker S, Ott C, Schneider MP, Schmieder RE. Olmesartan improves pulse wave velocity and lowers central systolic blood pressure and ambulatory blood pressure in patients with metabolic syndrome. J Clin Hypertens. 2015;17(2):98-104. 